\title{
PENETAPAN KADAR FLAVONOID EKSTRAK DAUN SINGKIL (Premna corymbosa) BERDASARKAN VARIASI SUHU DAN WAKTU PENGERINGAN SIMPLISIA
}

\author{
Determination of Flavonoid Levels of Extract Leaves (Premna Corymbosa) Based on \\ Temperature Variation and Time of Simplisian Drying
}

Risa Supriningrum, Reksi Sundu, Dwi Setyawati

Akademi Farmasi Samarinda

risa akfar@yahoo.com

08125872605

\begin{abstract}
Singkil leaves contain secondary metabolite compounds in the form of flavonoids, saponins, tannins and triterpenoids / steroids. Drying is one stage of making simplicia done so that simplicia is not easily damaged. This study aims to determine the level of flavonoid of ethanol extract of singkil leaves based on temperature variation and simplicia drying time. Research stages include sampling, plant determination, making of simplicia with oven drying at $50{ }^{\circ} \mathrm{C}$ and $70{ }^{\circ} \mathrm{C}$ with time 8 and 10 hours, maceration extraction, phytochemical extract screening, determination of flavonoid levels using UV-Vis Spectrophotometry. The results showed that ethanol extract of singkil leaves have secondary metabolite compound that is tannin, flavonoid, saponin and terpenoid / steroid. The average content of flavonoid ethanol extract of singkil leaves based on temperature and drying time of consecutive simplicia ranging from the highest is $50^{\circ} \mathrm{C}$ temperature at 10 hours of 1,54\%; temperature of $70{ }^{\circ} \mathrm{C}$ at 8 hours by 1,50\%; the temperature of $70{ }^{\circ} \mathrm{C}$ at 10 hours is $1,38 \%$ and the temperature is $50{ }^{\circ} \mathrm{C}$ at 8 hours by $0,96 \%$.
\end{abstract}

Keywords: Premna corymbosa Rottl et Willd, flavonoid levels, temperature, time

\begin{abstract}
Abstrak
Daun singkil memiliki kandungan senyawa metabolit sekunder berupa flavonoid, saponin, tanin dan triterpenoid/steroid. Pengeringan merupakan salah satu tahap pembuatan simplisia yang dilakukan agar simplisia tidak mudah rusak. Penelitian ini bertujuan untuk mengetahui kadar flavonoid ekstrak etanol daun singkil berdasarkan variasi suhu dan waktu pengeringan simplisia. Tahapan penelitian meliputi pengambilan sampel, determinasi tumbuhan, pembuatan simplisia dengan pengeringan oven pada suhu $50^{\circ} \mathrm{C}$ dan $70{ }^{\circ} \mathrm{C}$ dengan waktu 8 dan 10 jam, ekstraksi secara maserasi, skrining fitokimia ekstrak, penetapan kadar flavonoid menggunakan Spektrofotometri UV-Vis. Hasil penelitian menunjukkan bahwa ekstrak etanol daun singkil memiliki senyawa metabolit sekunder yaitu tanin, flavonoid, saponin dan terpenoid/steroid. Kadar rata-rata flavonoid ekstrak etanol daun singkil berdasarkan suhu dan waktu pengeringan simplisia berturut-turut mulai dari yang tertinggi adalah suhu $50^{\circ} \mathrm{C}$ waktu 10 jam sebesar $1,54 \%$; suhu $70{ }^{\circ} \mathrm{C}$ waktu 8 jam sebesar $1,50 \%$; suhu $70 \stackrel{\circ}{\circ}$ waktu 10 jam sebesar $1,38 \%$ dan suhu $50 \stackrel{\circ}{ } \mathrm{C}$ waktu 8 jam sebesar $0,96 \%$.
\end{abstract}

Kata kunci : Premna corymbosa Rottl et Willd, kadar flavonoid, suhu, waktu 


\section{PENDAHULUAN}

Tumbuhan singkil adalah salah satu tumbuhan obat yang ada di Indonesia. Tumbuhan ini merupakan jenis tumbuhan yang sering digunakan masyarakat Melayu sebagai sayur. Selain sebagai sayur, daunnya dapat digunakan sebagai obat tradisional untuk menyembuhkan berbagai penyakit seperti masuk angin, mengurangi atau menghilangkan bau nafas tak sedap, obat asma, hepatoprotektif, antitumor, infeksi cacing, dapat juga untuk menyegarkan tubuh wanita setelah melahirkan serta dapat memperbanyak air susu ibu [1].

Penelitian oleh Liya [2] tentang karakterisasi dan skrining fitokimia daun singkil (Premna corymbosa Rottl. et Willd) menyatakan daun singkil mengandung metabolit sekunder flavonoid, saponin, tanin dan triterpenoid/steroid. Tumbuhan Premna cordifolia mengandung flavonoid yang terdiri dari luteolin dan apigenin. Senyawa bioaktif yang spesifik dari kelompok flavonoid adalah apigenin dan luteolin yang memiliki banyak manfaat antara lain sebagai anti inflamasi, antioksidan, anti kanker dan dapat membantu proses pembekuan darah [3]

Flavonoid merupakan salah satu senyawa golongan fenol alam terbesar dan terdapat dalam semua tumbuhan hijau sehingga akan ditemukan pada setiap telaah ekstrak tumbuhan [4]. Flavonoid diketahui memiliki sifat sebagai penangkap radikal bebas atau bersifat antioksidan, penghambat enzim hidrolisis dan oksidatif dan bekerja sebagai antiinflamasi [5].

Salah satu faktor yang berpengaruh terhadap mutu simplisia adalah proses pengeringan [6]. Penelitian oleh Kencana [7] tentang pengaruh suhu dan lama pengeringan terhadap karakteristik teh herbal daun katuk (Sauropus adrogynus L. Merr) menggunakan suhu pengeringan $50^{\circ} \mathrm{C}$, $60{ }^{\circ} \mathrm{C}$ dan $70{ }^{\circ} \mathrm{C}$ dengan lama pengeringan 2, 3 dan 4 jam, diperoleh kadar vitamin $C$ tertinggi pada suhu 50 ${ }^{\circ} \mathrm{C}$ dengan lama pengeringan 2 jam. Penelitian Amanto, dkk [8] menyimpulkan, bahwa variasi suhu dan waktu pengeringan berpengaruh terhadap kadar kurkumin temu giring.

Berdasarkan uraian di atas, maka dilakukan penelitian tentang penetapan kadar flavonoid ekstrak etanol daun singkil berdasarkan variasi suhu dan waktu pengeringan simplisia. Suhu yang digunakan pada penelitian ini adalah $50^{\circ} \mathrm{C}$ dan $70{ }^{\circ} \mathrm{C}$ dengan waktu pengeringan 8 dan 10 jam.

\section{METODE PENELITIAN}

\section{Alat dan Bahan}

Alat yang digunakan dalam penelitian adalah alat-alat gelas (iwaki-pyrex), cawan porselen, neraca analitik (Shimadzu), oven (Shimadzu), pengayak mesh 60, spektrofotometr UV-Vis (Shimadzu), tangas air, desikator.

Bahan yang digunakan adalah air suling, alumunium klorida (Merck), amil alkohol (Merck), asam asetat anhidrat (Merck), asam sulfat (Merck), daun singkil muda dari Desa Loa Kulu, Kecamatan Tenggarong, Kabupaten Kutai Kartanegara , etanol $70 \%$ (OneMed), $\mathrm{FeCl}_{3}$ (Merck) , kalium asetat (Merck), kuersetin, serbuk Mg (Merck) , n-heksan (Merck), pereaksi Bouchardat, pereaksi Dragendrof, pereaksi Mayer.

\section{Prosedur Penelitian}

\section{Pengolahan Sampel}

Sampel berupa daun singkil muda diolah menjadi simplisia dengan 
pengeringan oven pada suhu $50^{\circ} \mathrm{C}$ dan $70{ }^{\circ} \mathrm{C}$ serta waktu pengeringan 8 dan 10 jam. Selanjutnya sampel dihaluskan dan diayak menggunakan pengayak mesh 60 .

\section{Penetapan Kadar Air Simplisia}

Sebanyak 2 gram simplisia dimasukkan ke dalam cawan porselen, dipanaskan dalam oven pada suhu $105^{\circ} \mathrm{C}$ selama 30 menit dan dikeringkan hingga bobot tetap. Susut pengeringan dihitung dengan rumus sebagai berikut :

$$
\begin{aligned}
& \text { Kadar Air }=\frac{b-(c-a)}{b} \times 100 \% \\
& \text { Keterangan : } \\
& \mathrm{a}=\text { Berat cawan } \\
& \mathrm{b}=\text { Berat sampel } \\
& \mathrm{c}=\text { Berat cawan }+ \text { sampel }
\end{aligned}
$$

\section{Ekstraksi Daun Singkil}

Sebanyak 100 gram serbuk daun singkil dimaserasi dengan $500 \mathrm{ml}$ pelarut etanol $70 \%$. Diaduk sesekali pada 6 jam pertama, selanjutnya didiamkan selama 18 jam. Selanjutnya disaring dan ampas dimaserasi kembali dengan pelarut etanol $70 \%, 500 \mathrm{ml}$. Seluruh maserat yang diperoleh dipekatkan di atas tangas air hingga diperoleh ekstrak kental

\section{Skrining Fitokimia}

Skrinng fitokimia dilakukan untuk mengidentifikasi golongan senyawa alkaloid, flavonoid, tannin dan saponin , steroid/terpenoid yang terkandung dalam ekstrak daun singkil.

\section{Penetapan Kadar Flavonoid}

Larutan induk kuersetin dibuat 100 ppm, larutan seri standar 2 ppm, 4 ppm 6 ppm, 8 ppm, 10 ppm dan larutan blanko. Dilakukan penetapan panjang gelombang serapan maksimum dan pembuatan kurva kalibrasi.
Larutan uji ekstrak etanol daun singkil ditimbang $10 \mathrm{mg}$, dilarutkan dengan etanol $70 \%$ dalam labu ukur $10 \mathrm{ml}$, sehingga diperoleh larutan dengan konsentrasi 1000 ppm. Dilakukan pengenceran larutan uji hingga diperoleh konsentrasi 100 ppm. Larutan 100 ppm dipipet sebanyak 0,5 ml dimasukkan ke dalam tabung reaksi dan ditambah $1,5 \mathrm{ml}$ etanol $70 \% ; 0,1$ $\mathrm{ml}$ alumunium klorida $10 \% ; 0,1 \mathrm{ml}$ kalium asetat $1 \mathrm{M}$ dan $2,8 \mathrm{~mL}$ air suling, dikocok hingga homogen. Larutan diinkubasi pada suhu kamar selama 30 menit, kemudian dilakukan pengukuran kadar flavonoid dengan spektrofotometer UV-Vis. Kadar dihitung dengan rumus sebagai berikut:

$$
\% \text { Kadar }=\frac{\mathbf{c}\left(\frac{\mathbf{m g}}{\mathbf{L}}\right) \cdot \mathbf{v} \cdot \mathbf{f} \mathbf{p} \cdot \mathbf{1 0}^{-3}}{\text { Berat Sampel }} \times 100 \%
$$

Keterangan :

$\mathrm{C}=$ Konsentrasi

$\mathrm{V}=$ Volume Sampel

$\mathrm{Fp}=$ Faktor Pengenceran

\section{Analisa Data}

Metode analisis data yang digunakan adalah metode deskriptif yang didasarkan pada data hasil penetapan kadar flavonoid berdasarkan variasi suhu dan waktu pengeringan.

\section{HASIL DAN PEMBAHASAN}

\section{Penetapan Kadar Air}

Penetapan kadar air dilakukan untuk memberikan batasan maksimal atau rentang besarnya kandungan air dalam suatu simplisia. Nilai maksimal yang diperbolehkan terkait dengan kemurnian dan kontaminasi [9].

Konsistensi ekstrak berdasarkan kadar air yang diperoleh pada pengeringan suhu $50^{\circ} \mathrm{C}$ dengan waktu 8 dan 10 jam termasuk kategori ekstrak kental dan pada suhu $70^{\circ} \mathrm{C}$ dengan waktu 8 dan 10 jam termasuk kategori ekstrak 
kering. Suatu ekstrak dikategorikan ekstrak cair apabila kadar air 30\%, ekstrak kental dengan kadar air 5-30\% dan ekstrak kering dengan kadar air kurang dari 5\% [10],. Hasil yang diperoleh pada penetapan kadar air menunjukkan semakin tinggi suhu dan lama pengeringan simplisia menyebabkan kadar air di dalam ekstrak semakin kecil hal ini disebabkan pada suhu tinggi air yang terkandung pada simplisia tersebut lebih banyak menguap dibandingkan dengan pengeringan dengan suhu rendah.

Tabel 1. Kadar Air Ekstrak Etanol Daun Singkil

\begin{tabular}{c|c|c}
\hline $\begin{array}{l}\text { Suhu/Waktu } \\
\left({ }^{0} \mathrm{C} / \mathrm{jam}\right)\end{array}$ & $\begin{array}{c}\text { Berat } \\
\text { ekstrak }(\mathrm{g})\end{array}$ & $\begin{array}{c}\text { Rata-rata } \\
\text { kadar air } \\
(\%)\end{array}$ \\
\hline $\mathbf{5 0} / \mathbf{8}$ & 2 & $\mathbf{8 , 6 5}$ \\
\hline $\mathbf{5 0} / \mathbf{1 0}$ & 2 & 7,56 \\
\hline $\mathbf{7 0} / \mathbf{8}$ & 2 & 4,79 \\
\hline $\mathbf{7 0} / \mathbf{1 0}$ & 2 & 3,85 \\
\hline
\end{tabular}

\section{Skrining Fitokimia}

Skrining fitokimia dilakukan untuk mengetahui kandungan senyawa metabolit sekunder yang terdapat dalam ekstrak etanol daun singkil dengan menggunakan pereaksi tertentu. Pengujian dilakukan terhadap semua perlakuan pengeringan. Hasil yang diperoleh pada skrining fitokima menunjukkan bahwa ekstrak sampel tidak mengandung senyawa alkaloid, karena dari 3 pereaksi yang digunakan hanya 1 perekasi yang memberikan hasil positif, yaitu pereaksi Bouchardat, dengan terbentuknya endapan coklat hitam. Pengujian tanin menunjukkan hasil positif setelah ditetesi dengan larutan $\mathrm{FeCl}_{3} 1 \%$ yaitu terbentuknya warna hijau kehitaman. Pengujian flavonoid hasil positif dengan terbentuknya warna kuning pada lapisan amil alkohol. Pengujian saponin menunjukkan hasil positif, karena terbentuk busa permanen pada saat dikocok dan setelah ditambahkan $\mathrm{HCl}$
2N busa tidak hilang (permanen). Pengujian steroid menunjukkan hasil positif dengan terbentuknya warna biruhijau.

Tabel 2. Hasil Skrining Fitokimia Ekstrak Etanol Daun Singkil

\begin{tabular}{|c|c|c|c|}
\hline Golongan & $\begin{array}{l}\text { Suhu } \\
50^{\circ} \mathrm{C}\end{array}$ & $\begin{array}{l}\text { Suhu } \\
70^{\circ} \mathrm{C}\end{array}$ & $\begin{array}{l}\text { Suhu } \\
50^{\circ} \mathrm{C}\end{array}$ \\
\hline & $8 \mathrm{jam}$ & $10 \mathrm{Jam}$ & $8 \mathrm{jam}$ \\
\hline Alkaloid & $(-)$ & $(-)$ & $(-)$ \\
\hline Tanin & $(+)$ & $(+)$ & $(+)$ \\
\hline Flavonoid & $(+)$ & $(+)$ & $(+)$ \\
\hline Saponin & $(+)$ & $(+)$ & $(+)$ \\
\hline Steroid & (+) & $(+)$ & $(+)$ \\
\hline
\end{tabular}

Keterangan :

$(+)$ = Mengandung golongan senyawa metabolit sekunder

( - ) = Tidak Mengandung Golongan Senyawa Metabolit Sekunder

\section{Penetapan Kadar Flavonoid}

Penetapan kadar flavonoid menggunakan metode kolorimetri dengan pereaksi alumunium klorida. Prinsip metode tersebut adalah terjadinya pembentukan kompleks antara alumunium klorida dengan gugus keto pada atom C-4 dan gugus hidroksi pada atom $\mathrm{C}-3$ atau C-5 yang bertetangga dari golongan flavon dan flavonol. Senyawa yang digunakan sebagai standar pada penetapan kadar flavonoid ini adalah kuersetin, karena kuersetin merupakan flavonoid golongan flavonol yang memiliki gugus keto pada atom C-4 dan juga gugus hidroksil pada atom C-3 dan C-5 yang bertetangga [11].

Pengukuran serapan panjang gelombang maksimum dilakukan pada rentang antara 350-550 nm. Penetapan panjang gelombang maksimum digunakan untuk mengukur serapan kurva kalibrasi dan sampel. Sedangkan pembuatan blangko bertujuan untuk kalibrasi sebagai larutan pembanding dalam analisis, larutan yang digunakan untuk membuat titik nol konsentrasi dari 
grafik kalibrasi. Pada penetapan kadar flavonoid, perlakuan inkubasi selama 30 menit dimaksudkan agar reaksi berjalan sempurna, sehingga memberikan intensitas warna yang maksimal.

Berdasarkan hasil pengukuran dengan spektrofotometer UV-Vis dan perhitungan berdasarkan rumus, diperoleh kadar rata-rata flavonoid adalah sebagai berikut pada suhu 50 ${ }^{0} \mathrm{C}$ waktu 8 jam sebesar $0,96 \%$, suhu $50{ }^{\circ} \mathrm{C}$ waktu 10 jam sebesar $1,54 \%$, suhu $70{ }^{\circ} \mathrm{C}$ waktu 8 jam sebesar 1,50 $\%$ dan suhu $70{ }^{\circ} \mathrm{C}$ waktu 10 jam sebesar $1,38 \%$. Pengeringan dengan suhu $50{ }^{\circ} \mathrm{C}$, waktu 10 jam memiliki kadar flavonoid paling tinggi, karena suhu optimal yang digunakan pada pengeringan simplisia yaitu antara $30^{\circ} \mathrm{C}$ sampai $60{ }^{\circ} \mathrm{C}$ [12] , sehingga ketika suhu dinaikkan ke $70^{\circ} \mathrm{C}$ kadar flavonoid pada ekstrak etanol daun singkil menjadi turun. Selain itu senyawa flavonoid tidak tahan terhadap pemanasan dan mudah teroksidasi pada suhu tinggi [13]. Suhu $50{ }^{\circ} \mathrm{C}$ dengan waktu pengeringan 8 jam memiliki kadar flavonoid yang paling rendah dikarenakan waktu pengeringannya yang kurang optimal dibandingkan dengan suhu $50^{\circ} \mathrm{C}$, waktu pengeringan 10 jam, suhu $70{ }^{\circ} \mathrm{C}$ dengan waktu pengeringan 8 jam dan suhu $70{ }^{\circ} \mathrm{C}$ dengan waktu pengeringan 10 jam. Penelitian yang dilakukan oleh Adri dkk [14] pada pengolahan teh herbal daun sirsak suhu pengeringan $50{ }^{\circ} \mathrm{C}, 60^{\circ} \mathrm{C}$ dan $70^{\circ} \mathrm{C}$ dengan waktu pengeringan 100 menit, 180 menit dan 200 menit, diperoleh hasil suhu dan lama pengeringan terbaik yaitu $60{ }^{\circ} \mathrm{C}$ dengan waktu 180 menit.

\section{KESIMPULAN DAN SARAN}

\section{Kesimpulan}

Kadar rata-rata flavonoid ekstrak etanol daun singkil berdasarkan suhu dan waktu pengeringan simplisia berturutturut mulai dari yang tertinggi adalah suhu $50{ }^{\circ} \mathrm{C}$ waktu 10 jam sebesar $1,54 \%$; suhu $70{ }^{\circ} \mathrm{C}$ waktu 8 jam sebesar $1,50 \%$; suhu $70{ }^{\circ} \mathrm{C}$ waktu 10 jam sebesar $1,38 \%$ dan suhu $50{ }^{\circ} \mathrm{C}$ waktu 8 jam sebesar 0,96\% .

\section{DAFTAR PUSTAKA}

[1] Marbun EMA., Restuati M. 2015. Pengaruh Ekstrak Daun BuasBuas (Premna pubescens Blume) Sebagai Antiinflamasi pada Edema Kaki Tikus Putih (Rattus novergicus). Jurnal Biosains Vol 1 No. 3.

[2] Liya. 2016. Karakterisasi dan Skrining Fitokimia Daun Singkil (Premna corymbosa Rottl \& Willd). 9Karya Tulis IImiah). Samarinda: D-III Farmasi Akademi Farmasi Samarinda.

[3] Restuati M, llyas S, Hutahaean S, Sipahutar H. 2014. Kajian Respon Imunitas Humoral Tikus Putih (Rattus novergicus L.) dengan Menggunakan Ekstrak Etanol Daun Buas-Buas (Premna pubescens Blume). (Digital Repository). Medan: Universitas Negri Medan.

[4] Markham KR. 1988. Cara Mengidentifikasi Flavonoid. Diterjemahkan oleh Kosasih P. Bandung: ITB.

[5] Pourmourad F, Hosseinimehr SJ, Shahabimajd N. 2006. Antioxidant Activity, Phenol And Flavonoid Contents Of Some Selected Iranian Medicinal Plants. African journal of Biotechnology. 5(11).

[6] Departemen Kesehatan Republik Indonesia. 2000. Parameter Standar Umum Ekstrak Tumbuhan Obat. Jakarta: Depkes. Hal: 10-11.

[7] Kencana ED. 2015. Pengaruh Suhu dan Lama Pengeringan Terhadap Karakteristik Teh Herbal 
Daun Katuk (Sauropus adrogynus L. Merr). Jurnal Penelitian. Hal : 6.

[8] Amanto, Bambang S, Siswanti, Atmaja, Angga. 2015. Kinetika Pengeringan temu giring (Curcuma heyneana Valeton \& Van Zijp) Menggunakan Cabinet Dryer Dengan Perlakuan Pendahuluan Blanching. Jurnal Teknologi Hasil Pertanian. 8(2): 114.

[9] Departemen Kesehatan Republik Indonesia. 2008. Farmakope Herbal Indonesia. Edisi I. Jakarta: DepKes RI. Hal: 174.

[10] Voigt. 1995. Buku Pelajaran Teknologi Farmasi. Diterjemahkan Soewandi, S.N.. Yogyakarta : Universitas Gajah Mada. Hal : 577.

[11] Azizah DN, Kumolowati E, Faramayuda F. 2014. Penetapan Kadar Flavonoid Metode $\mathrm{AlCl}_{3}$ pada ekstrak methanol kulit buah kakao (Theobromo cacao L.). (Jurnal IImiah). Cimahi: Universitas Jendral Achmad Yani. Hal: 48.

[12] Departemen Kesehatan Republik Indonesia. 1985. Cara Pembuatan Simplisia. Jakarta. Hal: 10-11.

[13] Rompas RA., Edy HJ, Yudistira A. 2012. Isolasi dan Identifikasi Flavonoid dalam Daun Lamun (Syringodium Isoetifolium). Jurnal IImiah Pharmacon. 1(2): 59-63.

[14] Adri D, Hersoelistyorini W. 2013. Aktivitas Antioksidan dan Sifat Organoleptik Teh Daun Sirsak (Annona muricata Linn.) Berdasarkan Variasi Lama Pengeringan. (Jurnal IImiah). Semarang: Universitas Muhammadiyah Semarang. Hal : 3-7 